\title{
Food Security and Nutrition Interventions in Response to the Aids Epidemic: Assessing Global Action and Evidence
}

\author{
Noora-Lisa Aberman • Rahul Rawat $\cdot$ \\ Scott Drimie $\cdot$ Joan M. Claros $\cdot$ Suneetha Kadiyala
}

Published online: 19 June 2014

(c) Springer Science+Business Media New York 2014

\begin{abstract}
The number of people receiving antiretroviral therapy in developing countries has increased dramatically. The last decade has brought an increased understanding of the interconnectedness between HIV/AIDS, food insecurity, and undernutrition and a surge of evidence on how to address the food security and nutrition dimensions of the epidemic. We review this evidence as well as the corresponding evolution of policy support for incorporating food security and nutrition concerns into HIV programming. The available evidence, although varied in scope and methodologies, shows that nutrition supplementation and safety nets in the form of food assistance and livelihood interventions have potential in certain contexts to improve food security and nutrition outcomes in an HIV/AIDS context. In the face of funding uncertainties and competing
\end{abstract}

\section{N.-L. Aberman}

Development Strategy and Governance Division, International Food Policy Research Institute, Lilongwe, Malawi

R. Rawat

Poverty, Health and Nutrition Division, International Food

Policy Research Institute, Dakar, Senegal

\section{S. Drimie}

Department of Interdisciplinary Health Sciences, Stellenbosch University, Stellenbosch, South Africa

\section{J. M. Claros}

Programme and Innovation Division, Nutrition and HIV/AIDS

Policy, United Nations World Food Programme, Rome, Italy

\section{S. Kadiyala $(\square)$}

London School of Hygiene and Tropical Medicine, London, UK e-mail: s.kadiyala@cgiar.org; suneetha.kadiyala@1shtm.ac.uk

\section{S. Kadiyala}

Leverhulme Centre for Integrative Research on Agriculture and Health, London, UK priorities, we must maintain momentum towards effective and sustainable solutions to the epidemic through continued systematic research to inform policy and through the strengthening of monitoring systems to dynamically inform intervention development.

Keywords HIV/AIDS · Food security · Nutrition · Food assistance $\cdot$ Interventions $\cdot$ Africa

\section{Introduction}

The number of people receiving antiretroviral therapy (ART) in low and middle-income countries has increased dramatically over the last decade. The total number of people accessing HIV treatment increased by $63 \%$ from 2009 to 2011 and by $20 \%$ in just 1 year from 2010 to 2011 [1, 2]. With this scale-up in treatment, the annual number of AIDS-related deaths fell by $24 \%$ from its peak in 2005 to 1.7 million in 2011 [2]. At the same time, the socioeconomic dimensions of the causes and consequences of HIV and AIDS, especially in southern and eastern Africa are better understood, and evidence on how to address the epidemic comprehensively in resource-limited settings has been building [3-5].

However, significant challenges remain. As the crisis at the Global Fund in 2011 epitomized, the steady increases in HIV funding in the last decade were suddenly under question. For the first time in almost a decade, in 2010 the total funding for responding to the epidemic stagnated. Although it bounced back in 2011, the anticipation of longterm commitments created uncertainty amongst governments and their partners [6,7].

At the same time, as more people are receiving treatment, retaining them in care has become the next big challenge [8]. Food insecurity and chronic undernutrition 
remain widespread in eastern and southern Africa, where the epidemic is most severe, further complicating a comprehensive response to the epidemic. The last decade has seen a surge of evidence on the interconnectedness between HIV/AIDS, food insecurity, and undernutrition. The AIDS epidemic precipitates and exacerbates food insecurity and undernutrition $[5,9,10]$. The spread of the virus can also be accelerated when coping behaviors adopted to mitigate the negative impacts on food security increase risk of HIV transmission [11-13].

The evidence base continues to grow. Food insecurity has been purported to lead to HIV acquisition and disease progression through nutritional, mental health, and behavioral pathways [13-15]. Wasting and underweight among people living with HIV (PLHIV) is a strong risk factor for mortality $[16,17]$, even among people receiving ART [1820]. Recent evidence from a research collaboration between The AIDS Service Organization (TASO) in Uganda and the Regional Network on AIDS, Livelihoods and Food Security (RENEWAL), which was coordinated by the International Food Policy Research Institute (IFPRI), provides further evidence on the relationship between food and nutrition insecurity and nutritional, clinical and survival outcomes among PLHIV. Both household food security and individual dietary quality - a proxy for nutrient adequacy-independently predicted underweight, wasting and quality of life among PLHIV [21, 22]. Further, the consumption of nutrient-rich foods was inversely associated with disease severity as measured by CD4 count, moderate anemia, and mortality [23].

The objectives of this paper are to briefly review the evolution of policies on food and nutrition in the context of HIV, to discuss common modalities of food and nutrition programmatic responses to HIV and review new evidence on the impact of such interventions, and to suggest future foci to strengthen the food and nutrition response to HIV.

\section{Policies on HIV, Food Security and Nutrition}

Over the last decade, the policy environment has increasingly recognized the importance of integrating food security and nutrition interventions into the response to the AIDS epidemic. In 2002, the World Food Programme (WFP) deployed a four-country mission to rethink food aid in the context of the AIDS epidemic in eastern and southern Africa [24]. In 2003, WFP's Executive Board approved the organization's first HIV policy that had a strong focus on impact mitigation. Also, WFP joined the Joint United Nations Programme on HIV/AIDS (UNAIDS), complementing the multisectoral response with its comparative advantage in the area food and nutrition, describing food as a powerful weapon in the fight against the disease $[25,26]$. Then, in 2005, the World Health Organization (WHO), in partnership with National Institutes of Health (NIH), held a consultation in Durban, South Africa. Following this consultation RENEWAL/IFPRI also convened a conference in Durban in 2005. These consultations resulted in a number of recommendations on integrating food security and nutrition as a critical component of a comprehensive global AIDS response. They culminated in a resolution approved by the World Health Assembly in May 2006.

Building global momentum, 2006 brought further progress towards integrating food and nutrition into the global AIDS policy. An e-forum consultation in advance of the second partnership forum of the Global Fund to Fight AIDS, Tuberculosis and Malaria urged that nutrition be considered a critical "complementary health product." In addition, the United States President's Emergency Plan for AIDS Relief (PEPFAR) finalized policy guidelines for using emergency plan funds to address food and nutrition needs. In FY2008 Authorization Bill, Congress stipulated that Office of the Global AIDS Coordinator (OGAC) "is directed to provide not less than $\$ 100,000,000$ for programs that address short-term and long-term approaches to food security as components of a comprehensive approach to fighting HIV/AIDS, and is encouraged to support programs that address the development and implementation of nutrition support, guidelines, and care services for people living with HIV/AIDS". This contributed to the proliferation of food by prescription (FBP) programming in southern and east Africa, highlighting the need to view food as medicine in the context of HIV and acute malnutrition.

PEPFAR subsequently refined the FBP program to become the nutrition assessment, counselling, and support (NACS) approach. This approach consists of clinical nutritional assessments and nutrition counseling and support-which sometimes includes the provision of specialized foods or micronutrient supplements-in clinical HIV setting. In addition, NACS includes a referral component, which promotes referrals to nutrition-sensitive interventions that can help improve food security and nutritional status, thereby improving health outcomes. The framework emphasizes the strengthening of links between nutritionspecific services and those provided by the health, agriculture, food security, social protection, education, and rural development sectors for more comprehensive care [27]. At the national level, PEPFAR has supported countries to take leadership of the responses to their respective epidemics and to expand the collective impact at the country level through increasing collaboration with multilateral organizations. This has led to the strengthening of a number of government programs including the array of national AIDS advisory councils. The 2009-2014 Ugandan 
Strategic Plan for nutrition, TB and HIV-Nutrition on the Context of HIV and Tuberculosis Infection-is an example of a national program emerging out of such collaboration, which clearly incorporates food and nutrition into the national AIDS response.

In 2008 UNAIDS published a policy brief that outlined their approach to HIV, food security, and nutrition [28]. It discussed the implications for food security and nutrition on prevention, treatment and care, support and impact mitigation. Furthermore, it recommended that international partners support the incorporation of effective food and nutrition interventions into multisectoral HIV programming. Additionally, the UNAIDS Outcome Framework for 2009-2011 outlined enhanced social protection for people affected by HIV as a priority area [29].

WFP's 2010 policy on HIV and AIDS envisions "a world in which nutritional support is integrated into treatment programs so that food insecure people on ART in low-income countries receive adequate nutritional support" [26]. WFP's policy framework addresses two main objectives. The first is ensuring nutritional recovery and treatment success through nutrition and food support. Program activities to meet this objective include nutrition assessment, education and counseling, as well as the provision of nutrition supplementation for undernourished PLHIV during the first 6 months of antiretroviral treatment. The second is mitigation of the effects of AIDS through safety nets wherein the WFP provides food assistance, usually in the form of a household food basket, to help mitigate the socio-economic effects of the disease on individuals and families [26]. Consolidating a decade of global momentum, WFP convened a round table on HIV, Food and Nutrition in Washington DC in 2012. A clear consensus emerged for closer collaboration to improve stakeholders' ability to integrate NACS into the HIV response. As a result of this consultation, an InterAgency Task Team (IATT) on HIV, food and nutrition was formed in 2012, chaired by WFP and representatives from UN organizations, academia and civil society, with the intention of being a strong voice to mainstream food and nutrition in the HIV response.

In 2012, led by UNDP, UNAIDS Cosponsors and the Secretariat prepared a guidance document to guide the investment framework for national AIDS response. The guidance note proposes two categories of programs and policies that address HIV and AIDS: critical enablers and development synergies. Critical enablers support basic program activities and tend to be HIV-specific-with HIV outcomes as the sole or primary objectives. Activities with a broader range of impacts across health and development sectors are seen as generating development synergies. These are seen as HIV-sensitive-with HIV outcomes as one of many objectives. Both categories are described as necessary for efficiently and effectively addressing the epidemic. This guidance document explicitly states that "food and nutrition interventions also act as both critical enablers and development synergies for treatment, care and support programme activities, depending on the exact context" [30].

Thus several policies and frameworks have been advanced to aid the integration of food and nutrition programs into a comprehensive response against the AIDS epidemic $[15,31,32]$. While each of these takes a slightly different approach, a similar line of thought flows through all: improvement in food security and nutrition of people infected with the virus and affected by the epidemic can address prevention as it may decrease risky behaviors; food security and nutrition programmatic responses can be seen as part of a care and treatment package as they aid recovery from malnutrition, and may improve drug adherence and decrease morbidity; and aforementioned improvements can mitigate socioeconomic impacts as they decrease stress on household human, economic, physical and social capital. In short, over the last decade the policy dialogue moved strongly toward consensus that food security and nutrition are necessary aspects of sustainably and holistically addressing the epidemic.

\section{Programmatic Responses to Foster Food Security and Nutrition}

With increasing recognition of the importance of integrating food security and nutrition interventions into HIV care and treatment programs, organizations involved in providing these services have been increasingly seeking to use targeted food assistance often linked to livelihood interventions [33, 34]. A multitude of objectives are often invoked: while some objectives are bio-medical and strictly PLHIV-focused, others are socio-economic in nature and focus on households. Objectives of these programmatic models, summarized below, include delaying the need to initiate ART from a medical standpoint; clinical, nutritional, and survival outcomes of PLHIV (those on ART and those not yet on ART, or ART-naïve); improving adherence to ART and retention in care; preventing impoverishment of households; and lowering the incidence of highrisk sexual behaviors due to food insecurity.

Due to the overlapping nature of the impacts of the epidemic, most interventions simultaneously address multiple objectives. Furthermore, interventions may have longterm impacts in addition to their intended immediate impacts. In fact, the effects of the epidemic on individuals, households and communities can be viewed as cyclical: the impacts of the epidemic in one cycle will determine the degree of resilience or vulnerability to future impacts [35]. 
Below we describe the key programmatic models aiming to improve food security and nutrition in an HIV context and review what we know about their impact on these outcomes. The broad predominant program models include:

- Nutrition supplementation interventions targeted to undernourished PLHIV, often using specialized foods, with nutrition assessment, counseling and support $(\mathrm{NACS})^{1}$ as a central component targeted to all PLHIV regardless of nutrition status.

- Safety nets (food, cash transfer or vouchers), targeted to HIV-affected households and individuals (such as OVC) to improve household food security, mitigate the impact of HIV.

- Livelihood interventions targeted to PLHIV households or communities heavily affected by the AIDS epidemic, sometimes linked to the above interventions which are limited in duration.

It is worth noting that interventions targeting individuals could potentially benefit the household. Also, many programs tend to combine nutrition supplementation to PLHIV with programs targeted to the affected households, for example, through household food basket or through livelihood interventions. Thus, in practice the distinction between the above programmatic modalities is often blurred.

\section{Nutrition Supplementation Interventions Targeted to PLHIV}

Indicators of undernutrition predict clinical and survival outcomes even among those on ART. Nutrition supplementation interventions, typically involve nutrition assessment and counseling and the provision of specialized foods given to undernourished PLHIV or those experiencing rapid weight loss. The current guidelines by WHO recommend supplementary feeding of mild-to-moderately undernourished adults (BMI $<18.5 \mathrm{~kg} / \mathrm{m}^{2}$ ) [36]. Typically micronutrient-fortified, blended flours (e.g. fortified corn soy blend) are provided, but additional types of supplementary foods such as lipid-based nutrient supplements can also be used. Severely undernourished PLHIV (BMI $<16 \mathrm{~kg} / \mathrm{m}^{2}$ ) should be provided with a therapeutic food, nutritionally equivalent to F100. The WHO guidelines support provision of therapeutic or supplemental feeding should be continued until BMI is stabilized above 16 or $16-18.5 \mathrm{~kg} / \mathrm{m}^{2}$, respectively, for two-to-three consecutive months [36].

\footnotetext{
${ }^{1}$ NACS is a critical component of for promoting optimal infant feeding practices to prevention of mother to child transmission of HIV and child survival, but a detailed discussion of this topic is beyond the scope of this paper.
}

These interventions, typically implemented for duration of three to 8 months, aim to treat undernutrition, reduce early mortality, as well as act as enablers for PLHIV to access and adhere to treatment and reduce the probability of mortality when ART is in initiated.

Rigorous empirical evidence on the impact of nutrition supplementation on nutritional, clinical, and treatment outcomes among PLHIV is just emerging from resourcepoor settings [5, 36-38]. The BAN (Breastfeeding, Antiretrovirals, and Nutrition) Study in Malawi recently published the results of a randomized $2 \times 5$ factorial design trial of lipid-based nutrient supplements and ART prophylaxis to HIV-infected mothers and their infants. The authors report that lipid-based nutrient supplements reduced weight loss among HIV-infected, breastfeeding women, both for those taking maternal antiretroviral prophylaxis to prevent postnatal HIV transmission and in those not receiving antiretroviral prophylaxis [39].

Another randomized supplementary feeding trial in Malawi compared the impact on BMI and fat-free body mass of wasted HIV patients starting ART who were supplemented with specialized, energy dense, ready-to-use, fortified (RUF) spread versus the more commonly used corn-soy blend (CSB) for a short duration of 14 weeks and a historical control group [40, 41]. Supplementary feeding with the RUF resulted in a greater increase in BMI and lean body mass than feeding with $\mathrm{CSB}$, but there were no significant observed differences in markers of disease progression, quality of life, or adherence to ART between RUF and CSB groups. But compared to the historical records of PLHIV receiving ART, but not nutrition supplementation, the RUF and CSB groups had higher BMI at 14 weeks but not at 26 weeks. The authors reported better treatment adherence outcomes among the supplemented group versus the historical control. Oketch et al. [42], in a cross-sectional comparison of the recipients and non-recipients of nutrition care and support program in South Africa, indicate that the benefits of the program on nutritional status and quality of life were rather small.

Micronutrient deficiencies are common among PLHIV in resource-limited settings, where diets are frequently inadequate to meet the recommended daily requirements. They are also more pronounced in individuals with advanced disease, as a consequence of reduced nutrient intake due to AIDS and opportunistic infections, and excessive losses due to alterations in absorption, metabolic disorders and diarrhea. Micronutrient malnutrition contributes to a weakening of immune status and thus a worsening of clinical condition among HIV-infected individuals. Interactions between immune function and specific nutrient deficiencies in HIV-1 disease have been reported for several trace elements and vitamins [43-45].

The results of the high dose multiple micronutrient supplementation trials in resource-limited settings are 
encouraging with benefits including improved CD4 cell count and survival among PLHIV [38, 46, 47]. Among HIV positive pregnant and lactating women in Tanzania, high dose multiple micronutrient supplementation also prevented adverse birth outcomes, reduced the risk of mother to child transmission, improved child growth during the first 2 years of life, and reduced child mortality in the first 2 years of life among children born to nutritionally vulnerable mothers with more advanced HIV disease [48, 49]. The findings of the studies investigating the effect of multiple micronutrients given at amounts close to the recommended dietary allowance [50-52] do not provide a clear direction given the heterogeneous nature of the study populations and the study design (for example, the study participants in Malawi [52] were co-infected with tuberculosis and the Kawai et al. [50] study in Tanzania did not include a placebo group). The impacts of supplementation with single nutrients (vitamin A, vitamin E, selenium, zinc, and iron) are still inconclusive. For example, an adverse effect of supplementation during pregnancy and lactation on mother-to-child transmission was observed when vita$\min \mathrm{A}(5,000 \mathrm{IU} / \mathrm{day})$ was combined with high-doses of $\beta$ carotene $(30 \mathrm{mg} /$ day). It is unclear whether this effect was due to $\beta$-carotene, vitamin A, or both [48]. But in South Africa and Malawi, Vitamin A did not have significant effect on mother-to-child transmission of HIV [53, 54]. We direct the reader to two recent comprehensive reviews [42, 50] on the outcome of single and multiple micronutrient trials.

Overall, the optimal formulation of a daily multiple micronutrients supplement, both in term of dose as well as the modality (e.g. a micronutrient supplement versus fortification of food) for HIV positive individuals living in chronically food and nutrition insecure regions requires further study. Studies are also required to ascertain the micronutrient needs and optimal supplement formulation among PLHIVs receiving ART and those not yet eligible for ART and those with and without co-infections. Based on the available evidence, WHO's current recommendation is to ensure intake of 1 recommended nutrient intake (RNI) for all micronutrients [55]. As the current WHO recommendations may not be enough to correct nutritional deficiencies among PLHIV in resource limited settings and nutritional needs may be high among PLHIV (for example, due to increased losses), The Academy of Sciences of South Africa recommends an intake of 1-2 RNI [56, 57].

While nutrition education and counseling is an important and integral part of the design of these programs, its operationalization, quality of implementation and its impact on behavioral and ultimately on nutritional, clinical and treatment outcomes needs further examination. Currently, we are not aware of any rigorous studies, outside of prevention of mother to child realm, examining the independent effects of nutrition education and counseling from nutrition supplementation.

\section{Safety Nets Targeted to HIV-Affected Households}

Safety net programs, in the form of food, cash or vouchers, aim to mitigate socioeconomic impacts of $\operatorname{HIV}[4,5]$.

Food assistance programs providing a household food basket targeted to food insecure PLHIV and their households, and/or to people affected by the epidemic such as orphans and vulnerable children, are the most ubiquitous of these program modalities. The duration of the food assistance is variable, usually ranging between 6 and 12 months, except for in the case of orphans where the duration of intervention may be longer. The primary objectives of these programs tend to be improving retention in care and treatment and mitigating the immediate socioeconomic impacts of HIV through improved food security in the short-term. For orphans, it may include improving their access to education and fostering attendance.

In Zambia, Cantrell et al. [58] report the results of a quasi-experimental food supplementation (in the form of WFP food basket) study, taking advantage of a staggered rollout of Zambia's ART program. The analysis compared adherence, CD4 counts, and weight gain outcomes among food insecure patients initiating ART and enrolled at the clinics where food was available with those enrolled at the control clinics where food assistance was not available. They find that while food supplementation improved drug adherence, they did not observe a statistically significant effect of food supplementation on weight gain and CD4 cell response.

In prospective cohort study in Haiti, Ivers et al. [59] show that food transfers, in the form of a WFP household food basket (comprised of cereals, dried legumes, CSB, vegetable oil and iodized salt) to food insecure PLHIV, improved their BMI, household food security and adherence to monthly clinic visits at the 12-month follow-up.

The results of these studies warrant caution, given their weak study design, as acknowledged by the authors. None of them account for important biases that may arise if there are unobserved characteristics that affect the probability of participation (or loss to follow-up) in the program that are also correlated with the outcomes of interest. Two important sources of this selection bias include targeting of the program to recipients or clinics based on characteristics unobservable to the researcher (or on which the researcher did not collect data) and self-selection into the program by eligible recipients.

The studies conducted through TASO-RENEWAL/IFPRI collaboration attempt to overcome such biases in two non-randomized studies on the impact of food assistance 
targeted to PLHIV (on ART and ART-naïve) and their households. Using TASO's retrospective cohort data from 2002 to 2007 in Uganda, Rawat et al. [60] estimated the impact of food assistance on weight gain and disease progression among 14,481 PLHIV. The authors employed propensity score matching with difference-in-difference to control for time-variant and time-invariant observable and time-invariant unobservable sources of bias in estimating the impact of household food assistance on disease progression and nutrition outcomes. Over 12 months, food assistance resulted in significant weight gain of $0.4 \mathrm{~kg}$ among PLHIV. The findings also reveal heterogeneous impacts: The impact on weight gain was greatest among individuals with the most advanced disease stage at baseline (almost $2 \mathrm{~kg}$ ) and among individuals not on ART $(0.4 \mathrm{~kg})$. The observation of a greater impact of food assistance among those with more advanced disease is consistent with the trajectory of disease progressionadvanced HIV disease is characterized by severe weight loss and wasting, and the potential to benefit may be greatest among these individuals. Household food ration slowed disease progression (measured as advancement in WHO disease staging) among ART-naïve PLHIV. Although statistically significant, the effect size was minimal.

The TASO-RENEWAL/IFPRI collaboration also recently concluded a 12-month prospective study evaluating the impact of a WFP monthly household food basket (cereals, legumes, CSB, sugar and vegetable oil) provided to food insecure ART-ineligible HIV-infected individuals for 12 months (August 2008-December 2010). This quasiexperimental design with a matched control group in two districts in Northern Uganda was nested within the routine programmatic context of both TASO and WFP. In Gulu district, WFP was operational when the study was initiated, providing a monthly household food ration to TASO clients meeting its criteria for food assistance, and served as the intervention district. In Soroti district, WFP was not operational, and served as the comparison district. 451 adult HIV-infected individuals were recruited from each district based on the following eligibility criteria: (1) eligibility for receipt of a WFP monthly household food basket, based on WFP's poverty assessment criteria, (2) non receipt of food assistance in the previous 12 months, (3) CD4 count between 200 and 459 cell $/ \mathrm{mm}^{3}$, and (4) ART naïve. In addition to matching at the individual and district levels, this study employed propensity score matching with difference-in-difference to estimate the causal impact.

The results of this study show a significant impact on anthropometry, but not CD4 count. Food assistance significantly increased BMI by $0.6 \mathrm{~kg} / \mathrm{m}^{2}$, and mid-upper arm circumference (MUAC) by $6.7 \mathrm{~mm}$ among people not eligible for ART. Food assistance resulted in an increase of hemoglobin count by approximately $1.0 \mathrm{~g} / \mathrm{dl}$ only among those with CD4 $>350$ cell $/ \mathrm{mm}^{3}$ [61]. This conditional impact of food assistance on hemoglobin by level of immunosuppression is likely related to dietary factors possibly comprising a larger attributable fraction for hemoglobin levels among individuals with less advanced HIV disease, when hemoglobin levels are less affected by HIV infection. When immunosuppression is more severe, HIV infection may play a larger role in lowering hemoglobin levels than dietary deficiencies. Also, though the food assistance basket contains micronutrient fortified commodities (CSB and vitamin A fortified vegetable oil), the composition of the package may be inadequate to meet the micronutrient requirements of our study population, and therefore might not be expected to have an impact on hemoglobin levels.

Although various food supplementation programs invoke household food security-related objectives, we did not identify studies estimating the impact of foods on household food security outcomes. A study undertaken in Kenya highlights key constraints, opportunities, and challenges relating to interventions aimed at strengthening the nutrition security of PLHIV on antiretroviral treatment. Through collaboration between AMPATH and RENEWAL/IFPRI, qualitative research was undertaken on a short-term nutrition intervention linked to the provision of free antiretroviral treatment for PLHIV in late 2005/early 2006 in western Kenya. Recipients of food reported increased dietary diversity and diet quantity and improved health status of other members of their households, especially young children. The majority (61\%) of clients reported that, as a result of the food supplementation, they regained enough strength to return to their household chores, farming activities, or income-earning activities. The amount of labor available in their household increased as the patient recuperated [62]. In the 12-month prospective TASORENEWAL study, food assistance increased household food security, but not individual dietary diversity: Household Food Insecurity Access Score increased by 2.1 points [61].

Brunelli et al. [63] use the WFP's cross-sectional Community and Household Survey data on the impact of food aid on child weight in five southern African countries. They find no significant difference in incidence of prime age adult death (HIV status unknown) between households that received food aid and those that did not. Except for Swaziland, all countries show smaller impacts of adult death on child weight among the households receiving food aid than the households not receiving the aid, suggesting that food aid mitigates the shock of prime age adult death on child nutrition.

In summary, the evidence on the impact of food assistance targeted to PLHIV and their households, from a limited number of studies of variable rigor and duration, 
show that food transfers have a significant and positive impact on anthropometry, retention in care and adherence to ART. The impact of food transfers on disease progression and other household welfare outcomes needs further study.

Cash transfers in the context of HIV are often used as a social safety net mechanism with aims such as improving food security, increasing educational attainment, and preserving assets for prevention and mitigation of socioeconomic impact of AIDS. Specific to the food and nutrition focus of this paper, cash transfers or vouchers can largely be seen as an alternative modality for delivering food transfers. Cash transfers and vouchers can cut down the costs of transporting and storing food and could potentially reduce the burden on health systems. Further, they provide the beneficiaries with some sense of dignity and choice, especially relevant in the context of HIV where stigma is an important concern.

But the literature remains scant on the impact of these alternate modalities to improve outcomes such as food security, nutrition status, retention in care and adherence to ART among those infected with or affected by HIV. Miller and Tsoka [64] interviewed 24 PLHIV who were the recipients of The Malawian Social Cash Transfer Scheme (SCT), a social protection program for ultra-poor and labor-constrained households, including PLHIV. The study respondents reported positive impacts on health, food security and economic well-being as well as an improved ability to care for their families.

Adato and Bassett [65] completed a comprehensive review of evidence on cash transfers implemented in the context of $\mathrm{HIV}$, and implications for the epidemic were extrapolated. We refer the reader to their full report [62] for an in-depth discussion on the matter, and some key points from the review are described here. First, broad evidence from studies on cash transfers shows that cash transfer programs, especially when conditioned upon school enrollment or health service utilization, are effective in reducing poverty and strengthening the human capital of children. In addition, unconditional cash transfer programs have been shown to increase food expenditure and food consumption. However, the ideal targeting of these programs in the context of HIV remains unclear, as it raises issues of stigma if targeted directly to AIDS-affected families and relies on the capacity of governments to effectively target. In addition, it is unclear whether individuals on antiretroviral treatment would benefit more from cash or food. As in the case of in-kind food transfers or vouchers, in light of concerns around accuracy, equity and stigma, Adato and Bassett suggest that consensus is building around targeting cash transfers (and indeed other forms of transfers), based on poverty and multiple vulnerability criteria, rather than targeting specifically to HIV affected families or other vulnerable groups.
Finally, knowledge gaps remain regarding the application of cash transfers in the context of HIV and AIDS. These include operational issues such as appropriate size of the transfer and flexibility under changing circumstances (e.g. prices, markets), number of transfers per household, when and how to transition households out of the program-hopefully into something better, the pace of scaling-up, and the role of NGOs and community-based organizations in program implementation and service delivery.

\section{Livelihood Interventions in the Context of HIV}

Recognizing that targeted nutrition supplementation and income transfers have a limited scope for sustainably addressing many of the complex challenges of the epidemic, several organizations are increasingly designing and implementing programs to strengthen the livelihoods of households and communities affected by the epidemic and thus improve their food security in the long-run.

A livelihood "comprises the capabilities, assets (stores, resources, claims, and access), and activities required for a means of living" [66]. While often focusing on food security as an outcome, a livelihoods approach emphasizes understanding people's means of achieving this outcome: their assets, the strategies which they adopt, the constraints they face and the strategies they are forced to depend on to achieve outcomes in terms of food security and accessing other basic requirements [67]. As such, successful livelihood programs in the context of HIV can potentially support a care and treatment strategy, mitigate negative household and community-level impacts, as well as sustainably prevent future infections.

In the context of HIV and AIDS, these programs typically consist of partnerships between HIV care and treatment organizations and livelihood program implementers. While the design of these programs varies, they support investment in some income creating activity, like smallscale agriculture, livestock, or sewing. They often entail the formation of groups to determine the targeting of services and some may require mandatory monetary and/or labor contributions from beneficiaries to enter the scheme [68]. As these programs are new, often small-scale and very context-specific, implementers are often "learning by doing". As such, implementers are just beginning to determine "best practices" [69, 70].

It is now well recognized that HIV progressively diminishes an individual's physical capacity and quality of life, alters household dependency ratios, skill structure, time allocation patterns, and resource allocation patterns [27]. It affects decision-making in terms of short-term versus long-term investments and norms of reciprocity and trust among community members. Stigma of HIV 
continues to be a prevalent phenomenon and threatens to hamper programmatic responses. These consequences portray some key dimensions of the epidemic, which have implications for how livelihood interventions are designed and implemented. What are the implications, for example, of mandatory contributions of beneficiaries in an HIV context where households frequently experience surging, often unpredictable, medical expenditures? The formation and use of groups to target services conforms well to current thinking on the importance of promoting social capital in development interventions. What are the implications for group cohesion and activities when the member is too ill? Program implementers responding to the AIDS epidemic are beginning to critically examine the theory of change for these interventions.

Research on how livelihood interventions need to be designed and implemented and their impact is just beginning to emerge $[68,71-73]$. The results of the studies are promising; findings from a village savings and loan program, implemented by CARE International in Côte d'Ivoire, revealed that when appropriate medical treatment is available, PLHIV participate and benefit from microfinance activities, and enhance their economic self-sufficiency [71]. This qualitative study reported that by bringing individuals with similar experiences together, savings and loan groups also acted as self-support groups providing psychosocial support while reducing stigmatization and increasing members' sense of dignity and self-worth. Wagner et al. [73] report similar perceived positive impact of a microcredit program targeted to PLHIV on ART in Uganda.

An operations research study employing a qualitative indepth case study approach, conducted under TASORENEWAL/IFPRI collaboration in Uganda aimed to explore the conceptual foundations and processes of livelihood interventions integrated into HIV care and treatment programs. The research focused on 16 TASO partner organizations that implement livelihood programs for TASO clients in 4 sites in Eastern and Northern Uganda. Using a program theory framework, semi-structured interviews were used to collect data from 3 to 4 staff members along the program chain in TASO and each of the 16 TASO partnering organizations that implement livelihood interventions (agriculture and non-agriculture interventions), and 71 TASO-registered households with PLHIV (interviewed, on average, three times) who had participated or were participating in livelihood interventions [68, 72]. Participants in both agricultural and non-agricultural livelihood interventions noted that program participation had increased the amount of food available to their households, as well as a range of non-food goods and services (such as medicines, schools fees, rent) which their participation in both agricultural and non-agricultural livelihood interventions allowed them to purchase. Some program participants reported that they felt physically better because they were less anxious about being able to afford food.

Program participants spoke of their increased ability to invest in business and expressed a sense of emancipation: "...if I made sales last night and I know my profits and would want to buy some eggs, I can go ahead. If I want some meat, [I] am free" (livelihood program participant, Jinja). A substantial number of participants reported the value of skills and knowledge acquisition.

Examination of program conceptualization and processes reveal several avenues for further investigation [68, 72]. For example, organizations involved in integrating livelihood interventions into HIV programs are increasingly looking towards the formation of groups (groups of PLHIV only or mixed groups of PLHIV and people of unknown HIV status) to target and deliver interventions. Roopnaraine et al. [72] report that group membership widely confers benefits in the form of psychosocial and motivational support, particularly in empowering individuals to access HIV services and handle stigma. But stigma attached to joining a group-based livelihood program comprising of PLHIV can hamper the realization of potential benefits. In addition, group-based livelihood programs were reported to increase the pool of labor and access to other goods and services; but joining fees, land and labor requirements for participation in these programs limit the potential for participation.

Overall, the studies suggest that livelihood interventions integrated into HIV care and treatment programs provide valuable benefits to participants at the individual, household and community level. Nonetheless, the TASO-RENEWAL/ IFPRI OR study highlights areas in which livelihood interventions could be strengthened to improve performance, efficiency and transparency. Specific programmatic suggestions for strengthening these areas are proposed. First, staff training should be institutionalized to strengthen the conceptual foundations of the program, in addition to their usual implementation related training. Second, clients should be enabled to have meaningful participation in program operations. Third, better engagement with complementary service providers should be undertaken to ensure that the envisioned design and implementation comes to fruition and yields maximum impact on participants. Fourth, monitoring systems should be strengthened. Finally, while group-based approaches have many benefits to participants, they are not appropriate in all settings.

\section{Future Directions}

Over the last decade, rapid advances have been made in science, in characterizing and quantifying the impacts, in 
organizational approaches, and in funding to fight the causes and consequences of the epidemic. At the same time, the evidence base around the importance of food security and nutrition in HIV prevention, treatment, and mitigation, is strengthening, albeit lagging in comparison to our understanding of the basic science of the disease. Nonetheless, there is now widespread recognition of the need to strengthen and mainstream food and nutrition programming into the HIV response.

The IATT on HIV, food and nutrition has highlighted the financial strain of funding for HIV specific programming as global health funding is shifting away from largescale investment in vertical approaches that target single diseases to horizontal approaches that reinforce integration of services, maternal and child health programs, primary care and efforts to strengthen health systems overall. In order to sustain the progress made by the HIV/AIDS response in this new environment, social protection, nutrition and food security will have to be effectively leveraged to support sustainable access to HIV prevention services, treatment, care and support (demand side) and complement health system strengthening efforts (supply side). Food and nutrition will need to continue to be integrated in the HIV/AIDS response and at the same time, an HIV-sensitive lens will need to be applied to the fields of health, education, social protection, food security and nutrition. Therefore, while in the past, food and nutrition programs were meant to be integrated in the HIV/AIDS response, as per the UNAIDS strategy, today's environment presents an opportunity for new strategic approaches making the fields of health and nutrition more HIVsensitive.

There are three distinct areas of focus in the nexus of HIV food and nutrition that require continued attention, which are also recognized by the IATT: (1) programming, (2) funding and advocacy, and (3) research. We further elaborate on these three priority areas.

\section{Programming}

While integration of NACS into HIV treatment, care and support services is an intended program objective, gaps remain in our understanding of how to achieve this integration. As part of a broader health system strengthening, specific attention needs to be prioritized for the food and nutrition components within the HIV response. Currently, retention of clients within HIV services remains a major impediment towards progress in combating HIV; large proportions of clients are lost between diagnosis and treatment initiation, and similarly during the first few months after ART initiation. The evidence suggests that food and nutrition interventions may improve client retention in the most difficult, early months of treatment. Therefore, strategies by service providers to ensure retention to services are needed, which will require concerted efforts to improve linkages between health facility-based nutrition services and community-based nutrition and food security services. Nutrition education and counseling remains a weak component and the documentation of lessons learnt in terms of what works and what does not in integrating nutrition education and counseling into HIV care and treatment requires attention.

\section{Funding and Advocacy}

After 2010, critical funding shortages for the AIDS response threatened to undermine effective programming across eastern and southern Africa. Research from Malawi, Swaziland and Zimbabwe highlighted the negative impact of the cancellation of Global Fund Round 11 funding on the HIV and TB response in the region. The report, funded by the Open Society Initiative for Southern Africa (OSISA) and the Open Society Foundations (OSF), detailed how the funding crisis severely undermined efforts to tackle HIV and AIDS in southern Africa [74]. The report appealed to the board of the Global Fund to issue a new call for applications as soon as possible and to emphasize the importance of investing in 'critical enablers' to increase the effectiveness of core program activities. In response to widespread concerns, the Global Fund approved and is now implementing a new funding mechanism that requires countries to develop National Strategy Plans that prioritize investing for results that effectively address 'critical enablers' including the integration of food and nutrition in national responses. A $30 \%$ increase in funds was pledged at the start of the 2011-2013, which represented the largest amount ever committed to fight against AIDS, tuberculosis and malaria.

This is an important development to ensure that key responses-including those that address food security and nutrition-are not neglected. Policy frameworks incorporating food become meaningless if they are not financed, and external sources have been the main drivers of these activities. There is now an opportunity for countries to develop innovative ways of supporting food security and nutrition interventions.

Parallel to coordinated fundraising activities, a concerted advocacy strategy should raise the profile of key issues: such as how food and nutrition interventions can help overcome barriers to access and retention, as well as benefit individuals and families affected by HIV, from prevention to mitigation of the consequences of HIV.

\section{Research}

Given the important relationship between diet quality and nutrition, quality of life, clinical and survival outcomes, 
further research is needed in the composition of food transfers to meet both macronutrient and micronutrient needs among both immunosuppressed and non-immunosuppressed PLHIV in resource-limited settings. More research is needed to understand which assistance modalities improve clinical and economic outcomes, and under what conditions. In Ecuador, for example, a recent impact evaluation of three different modalities of WFP transferscash, food vouchers, and food transfers-given to Colombian refugees found that voucher transfers led to the greatest increases in household dietary diversity [75]. However, no equivalent data exists on the comparative effectiveness of different transfer types among HIVinfected populations. Research on the role and impact of nutrition education and counseling are urgently needed. Studies investigating the overall welfare effects beyond nutritional and clinical, at PLHIV and household level in the short and long-term are also required.

When and how to transition from food transfers to livelihood support programs requires further investigation. A study of livelihood program and HIV care and treatment program implementers conducted under the TASORENEWAL/IFPRI collaboration offers no firm consensus about when clients should be expected to transition fully to livelihood activities. In part, this lack of consensus reflected a dearth of evidence to support any particular timeline. Some informants argued that livelihood activities should begin only after clients had started benefitting from the food and medicine. They believed that that initiating too many different educational components at once would be difficult for participants. Others suggested that livelihood activities should be started well before food assistance ends to emphasize the temporary nature of food assistance [76].

The findings of the research studies on the perceived impacts of livelihood programs integrated to HIV care and treatment are encouraging. However, carefully planned, implemented, and evaluated HIV-responsive livelihood programs continue to be scant. The findings from the studies on operational process show several opportunities to strengthen the impact of these livelihood interventions [72], which require further testing.

\section{Conclusion}

Much of the evidence detailed in this paper highlights the importance of food security and nutrition interventions, which raises the importance of focusing funding and programming more efficiently on HIV-food security and nutrition interventions. The available evidence, albeit of variable quality, shows that nutrition supplementation, safety nets - especially in the form of food assistance-and livelihood interventions have the potential to improve nutrition status, quality of life, retention in care, adherence to treatment, and household food security status among PLHIV. It is crucial to build on this evidence, in order to inform policy and programming. However, investments in systematically and proactively strengthening the evidence base to date remain poor and need to be ramped up.

Finally, we conclude with a call for action. Systematic research to inform policy and program actions cannot be conducted in a vacuum: program interventions are an opportunity to generate evidence for refinement of future interventions. Serious investments should be made to strengthen monitoring systems, integrate operations research and impact evaluations into the program design and implementation strategy to fully understand the range of impacts of these programs and to dynamically inform intervention development.

Acknowledgments We thank the editors for leading the development and design of this supplement. We also acknowledge the reviewers and editors for their valuable feedback and support. Financial support was received from the Regional Network on AIDS, Livelihoods and Food Security (RENEWAL) facilitated by the International Food and Policy Research Institute (IFPRI). RENEWAL is grateful for the support from Irish Aid and the Swedish International Development Cooperation Agency (SIDA).

\section{References}

1. World Health Organization. HIV/AIDS Fact Sheet. 7-20-0012. World Health Organization. 2012.

2. Joint United Nations Programme on HIV/AIDS (UNAIDS). UNAIDS World AIDS Day 2012 Global Fact Sheet. 2012. Geneva, Joint United Nations Programme on HIV/AIDS.

3. Chapoto A, Jayne TS, Socioeconomic characteristics of individuals afflicted by AIDS related prime age mortality in Zambia. In: Gillespie S, editor. AIDS, poverty, and hunger: challenges and responses. Washington DC: International Food Policy Research Institute; 2006. p. 33-55.

4. Gillespie S, Kadiyala S. HIV/AIDS and Food and Nutrition Security [7]. 2005. Food policy review. Washington DC: International Food Policy Research Institute.

5. Kadiyala S, Chapoto A. AIDS epidemic, nutrition, food security and livelihood: review of evidence in Africa. In: Sahn D, editor. The socio-economic dimensions of HIV/AIDS in Africa. Ithica: Cornel University Press; 2010. p. 74-109.

6. Deghaye N. Funding for HIV/AIDS in South Africa: sounding a warning note for civil society?. South Africa: Presentation to Oxfam affiliates; 2012.

7. Joint United Nations Programme on HIV/AIDS (UNAIDS). New Reports show philanthropic funding for AIDS down at pivotal moment in the response. 2011/2012. Geneva: UNAIDS.

8. Joint United Nations Programme on HIV/AIDS (UNAIDS). UNAIDS report on the global AIDS epidemic. Geneva: UNAIDS; 2012.

9. Beegle K, de Weerdt J, Dercon S. Adult mortality and consumption growth in the age of HIV/AIDS. Econ Dev Cult Change. 2008;56(2):299-326.

10. Yamano T, Jayne TS. Measuring the impacts of working-age adult mortality on small-scale farm households in Kenya. World Dev. 2004;32(1):91-119. 
11. Peters PE, Walker PA, Kambewa D. Striving for normality in a time of AIDS in Malawi. J Mod Afr Stud. 2008;46(4):659-87.

12. Bryceson DF. Risking death for survival: peasant responses to hunger and HIV/AIDS in Malawi. World Dev. 2014;34(9): 1654-66.

13. Weiser SD, Leiter K, Bangsberg DR, Butler LM, Korte FP, Hlanze Z, et al. Food insufficiency is associated with high-risk sexual behavior among women in Botswana and Swaziland. Plos Med. 2007;4(10):1589-98.

14. Tsai AC, Hung KJ, Weiser SD. Is food insecurity associated with HIV risk? Cross-sectional evidence from sexually active women in Brazil. Plos Med. 2012;9(4):e1001203.

15. Weiser SD, Young SL, Cohen CR, Kushel MB, Tsai AC, Tien $\mathrm{PC}$, et al. Conceptual framework for understanding the bidirectional links between food insecurity and HIV/AIDS. Am J Clin Nutr. 2011;94(6):1729S-39S.

16. Tang AM. Weight loss, wasting, and survival in HIV-positive patients: current strategies. AIDS Read. 2003;13(12 Suppl): S23-7.

17. van der Sande MAB, van der Loeff MFS, Aveika AA, Sabally S, Togun T, Sarge-Njie R, et al. Body mass index at time of HIV diagnosis: a strong and independent predictor of survival. J Acquir Immune Defic Syndr. 2004;37(2):1288-94.

18. Mangili A, Murman DH, Zampini AM, Wanke CA. Nutrition and HIV infection: review of weight loss and wasting in the era of highly active antiretroviral therapy from the nutrition for healthy living cohort. Clin Infect Dis. 2006;42(6):836-42.

19. Johannessen A, Naman E, Ngowi BJ, Sandvik L, Matee MI, Aglen HE, et al. Predictors of mortality in HIV-infected patients starting antiretroviral therapy in a rural hospital in Tanzania. BMC Infect Dis. 2008;8:52.

20. Zachariah R, Fitzgerald M, Massaquoi M, Pasulani O, Arnould L, Makombe S, et al. Risk factors for high early mortality in patients on antiretroviral treatment in a rural district of Malawi. AIDS. 2006;20(18):2355-60.

21. Kadiyala S, Rawat R. Food access and diet quality independently predict nutritional status among people living with HIV in Uganda. Public Health Nutr. 2012;16(01):164-70.

22. Palermo T, Rawat R, Sheri D, Kadiyala S. Food access and diet quality are associated with quality of life outcomes among HIVinfected individuals in Uganda. PLoS ONE. 2013;8(4):e62353.

23. Rawat R, McCoy SI, Kadiyala S. Poor diet quality is associated with low CD4 count and anemia and predicts mortality among antiretroviral therapy-naive HIV-positive adults in Uganda. J Acquir Immune Defic Syndr. 2013;62(2):246-53.

24. Kadiyala S, Gillespie S. Rethinking food aid to fight AIDS. Food Nutr Bull. 2004;25(3):271-82.

25. World Food Programme (WFP). Update on WFP's response to HIV/AIDS. Executive Board First Regular Session. Agenda item 4. Rome, 23-27 February 2004. Rome: WFP; 2004.

26. World Food Programme (WFP). WFP HIV and AIDS Policy. 2010. Rome: World Food Programme.

27. Food and Nutrition Technical Assistance II Project. Meeting on nutrition assessment, counselling, and support in HIV Services: strategies, tools, and progress. Washington DC: Food and Nutrition Technical Assistance; 2011.

28. Joint United Nations Programme on HIV/AIDS (UNAIDS). HIV, food security and nutrition policy brief. Geneva: UNAIDS; 2008.

29. United Nations Programme on HIV/AIDS (UNAIDS). Joint actions for results: UNAIDS outcome framework. Geneva: UNAIDS; 2009.

30. United Nations Development Programme (UNDP). Understanding and acting on critical enablers and development synergies for strategic investments. New York: Joint publication of UNDP and UNAIDS; 2012.
31. Gillespie S, Drimie S. Hyperendemic AIDS, food insecurity and vulnerability in southern Africa: a conceptual evolution., RENEWAL Working Paper SeriesWashington DC: International Food Policy Research Institute; 2009.

32. Frega R, Duffy F, Rawat R, Grede N. Food insecurity in the context of HIV/AIDS: a framework for a new era of programming. Food Nutr Bull. 2010;31(4):S292-312.

33. Food and Nutrition Technical Assistance Project. Nutrition, food security and HIV: a compendium of promising practices. Washington DC: Food and Nutrition Technical Assistance; 2008.

34. Nutrition and HIV/AIDS United Nations Administrative Committee on Coordination S-CoN. Nutrition and HIV/AIDS, Report of the 28th Session Symposium Held 3-4 April 2001, Nairobi, Kenya. UNAIDS - UNSSCN; 2001.

35. U.N.General Assembly (UNGASS). Political Declaration on HIV/AIDS: Intensifying our efforts to eliminate HIV/AIDS, 65th Session. New York: U.N.General Assembly (UNGASS); 2011.

36. World Health Organization. Essential prevention and care interventions for adults and adolescents living with HIV in resourcelimited settings. Geneve: WHO; 2008.

37. Koethe JR, Chi BH, Megazzini KM, Heimburger DC, Stringer JSA. Macronutrient supplementation for malnourished HIVinfected adults: a review of the evidence in resource-adequate and resource-constrained settings. Clin Infect Dis. 2009;49(5): 787-98.

38. De Pee S, Semba RD. Role of nutrition in HIV infection: review of evidence for more effective programming in resource-limited settings. Food Nutr Bull. 2010;31(4):S313-44.

39. Kayira D, Bentley ME, Wiener J, Mkhomawanthu C, King CC, Chitsulo $\mathrm{P}$, et al. A lipid-based nutrient supplement mitigates weight loss among HIV-infected women in a factorial randomized trial to prevent mother-to-child transmission during exclusive breastfeeding. Am J Clin Nutr. 2012;95(3):759-65.

40. Ndekha MJ, Oosterhout JJG, Zijlstra EE, Manary M, Saloojee H, Manary MJ. Supplementary feeding with either ready-to-use fortified spread or corn-soy blend in wasted adults starting antiretroviral therapy in Malawi: randomised, investigator blinded, controlled trial. Br Med J. 2009;338:b1867.

41. Van Oosterhout JJ, Ndekha M, Moore E, Kumwenda JJ, Zijlstra EE, Manary M. The benefit of supplementary feeding for wasted Malawian adults initiating ART. AIDS Care. 2010;22(6):737-42.

42. Oketch JA, Paterson M, Maunder EW, Rollins NC. Too little, too late: comparison of nutritional status and quality of life of nutrition care and support recipient and non-recipients among HIV-positive adults in KwaZulu-Natal, South Africa. Health Policy. 2011;99(3):267-76.

43. Friis H. Micronutrient interventions and HIV infection: a review of current evidence. Trop Med Int Health. 2006;11(12):1849-57.

44. Semba RD, Tang AM. Micronutrients and the pathogenesis of human immunodeficiency virus infection. Br J Nutr. 1999;81(3): $181-9$.

45. World Health Organization. Nutrient Requirements For people living with HIV/AIDS, Report of a technical consultation. Geneva: World Health Organization; 2003.

46. Irlam JH, Visser MME, Rollins NN, Siegfried N. Micronutrient supplementation in children and adults with HIV infection. Cochrane Database Syst Rev. 2010. doi:10.1002/14651858. CD003650.pub3.

47. Forrester JE, Sztam KA. Micronutrients in HIV/AIDS: is there evidence to change the WHO 2003 recommendations? Am J Clin Nutr. 2011;94(6):1683S-9S.

48. Fawzi WW, Msamanga GI, Hunter DJ, Renjifo B, Antelman G, Bang $\mathrm{H}$, et al. Randomized trial of vitamin supplements in relation to transmission of HIV-1 through breastfeeding and early child mortality. AIDS. 2002;16(14):1935-44. 
49. Fawzi WW, Msamanga GI, Spiegelman D, Wei R, Kapiga S, Villamor E, et al. A randomized trial of multivitamin supplements and HIV disease progression and mortality. N Engl J Med. 2004;351(1):23-32.

50. Kawai K, Kupka R, Mugusi F, Aboud S, Okuma J, Villamor E, et al. A randomized trial to determine the optimal dosage of multivitamin supplements to reduce adverse pregnancy outcomes among HIV-infected women in Tanzania. Am J Clin Nutr. 2010;91(2):391-7.

51. Kelly P, Katubulushi M, Todd J, Banda R, Yambayamba V, Fwoloshi M, et al. Micronutrient supplementation has limited effects on intestinal infectious disease and mortality in a Zambian population of mixed HIV status: a cluster randomized trial. Am J Clin Nutr. 2008;88(4):1010-7.

52. Semba RD, Kumwenda J, Zijlstra E, Ricks MO, van Lettow M, Whalen $\mathrm{C}$, et al. Micronutrient supplements and mortality of HIV-infected adults with pulmonary TB: a controlled clinical trial. Int J Tuberc Lung Dis. 2007;11(8):854-9.

53. Coutsoudis A, Pillay K, Spooner E, Kuhn L, Coovadia H, South African Vitamin A Study Group. Randomized trial testing the effect of vitamin A supplementation on pregnancy outcomes and early mother-to-child HIV-1 transmission in Durban, South Africa. AIDS. 1999;13(12):1517-24

54. Kumwenda N, Miotti PG, Taha TE, Broadhead R, Biggar RJ, Jackson JB, et al. Antenatal vitamin A supplementation increases birth weight and decreases anemia among infants born to human immunodeficiency virus-infected women in Malawi. Clin Infect Dis. 2002;35(5):618-24.

55. World Health Organization. Executive summary of a scientific review: consultation on nutrition and HIV/AIDS in Africa: Evidence, lessons, and recommendations for action. Durban, South Africa: WHO: Department of Nutrition for Health and Develoment; 2005 .

56. Spencer DC, Harmam C, Botha C. Nutrition and HIV/AIDS: Nutritional Guidelines for HIV-infected Adults and Children in Southern Africa: Meeting the Needs (Sections 3-6). The Southern African Journal of HIV Medicine; 2008.

57. The Academy of Science of South Africa. HIV/AIDS, TB, and Nutrition: Scientific inquiry into the nutritional influences on human immunity with special reference to HIV infection and active TB in South Africa. Pretoria: ASSAf; 2007.

58. Cantrell RA, Sinkala M, Megazinni K, Lawson-Marriott S, Washington $\mathrm{S}$, Chi $\mathrm{BH}$, et al. A pilot study of food supplementation to improve adherence to antiretroviral therapy among foodinsecure adults in Lusaka, Zambia. J Acquir Immune Defic Syndr. 2008;49(2):190-5.

59. Ivers LC, Chang Y, Gregory JJ, Freedberg KA. Food assistance is associated with improved body mass index, food security and attendance at clinic in an HIV program in central Haiti: a prospective observational cohort study. AIDS Res Ther. 2010;7:33.

60. Rawat R, Kadiyala S, McNamara P. The impact of food assistance on weight gain and disease progression among HIVinfected individuals accessing AIDS care and treatment services in Uganda. BMC Pub Health. 2010;10(1):316.

61. Rawat R, Faust E, Maluccio JA, Kadiyala S. The impact of a food assistance program on nutritional status, disease progression, and food security amoung poeple living with HIV in Uganda. J Acquir Immune Defic Syndr. 2014;66(1):e15-22.

62. Byron E, Gillespie S, Nangami M. Integrating nutrition security with treatment of people living with HIV: lessons from Kenya. Food Nutr Bull. 2008;29(2):87-97.

63. Brunelli C, Kenefick E, Yamauchi F. The Impact of Adult Death on child growth and nutrition: Evidence from five South African Countries. RENEWAL Brief No. 12. International Food Policy Research Institute; 2008.

64. Miller C, Tsoka MG. ARVs and cash too: caring and supporting people living with HIV/AIDS with the Malawi Social Cash Transfer. Trop Med Int Health. 2012;17(2):204-10.

65. Adato M, Bassett L. Social Protection and Cash Transfers to Strenghthen Families Affected by HIV and AIDS. IFPRI Research Monograph. Washington DC: International Food Policy Research Institute; 2012.

66. Chambers R, Conway G. Sustainable Rural Livelihood: Practical Concepts for the 21st century. IDS Discussion Paper [296]. Brighton: Institute of Development Studies; 1992.

67. Maxwell D, Sadler K, Sim A, Mutyoni M, Egan R, Webster M. Emergency Food Security Interventions. Humanitarian Practice Network Paper [10]. 2008. London, Overseas Development Institute.

68. Kadiyala S, Rawat R, Roopnaraine T, Babirye F, Ochai R. Applying a programme theory framework to improve livelihood interventions integrated with HIV care and treatment programmes. J Dev Eff. 2009;1(4):470-91.

69. Project Description Project Concern International (PCI). U S Department of State 2008. http://newdelhi.usembassy.gov/pep farprojectspci.html. Accessed 12 Mar 2013.

70. Regional Centre for Quality of Health Care (RCQHC) and the Food and Nutrition Technical Assistance (FANTA). Nutrition, food security and HIV: a compendium of promising practices. Washington DC: Academy for Educational Development (AED); 2008.

71. Holmes K, Winskell K, Hennink M, Chidiac S. Microfinance and HIV mitigation among people living with HIV in the era of antiretroviral therapy: emerging lessons from Cote d'Ivoire. Glob Public Health. 2011;6(4):447-61.

72. Roopnaraine T, Rawat R, Babirye F, Ochai R, Kadiyala S. "The group" in integrated HIV and livelihoods programming: opportunity or challenge? AIDS Care. 2012;24(5):649-57.

73. Wagner G, Rana Y, Linnemayr S, Balya J, Buzaalirwa L. A qualitative exploration of the economic and social effects of microcredit among people living with HIV/AIDS in Uganda. AIDS Res Treat. 2012;2012:318957.

74. Gonalez L. The First to go: How communities are being affected by the global fund crisis. Open Society Initiative for Southern Africa and Open Society Foundations; 2012.

75. Hidrobo M, Hoddinott J, Peterman A, Margolies A, Moreira V. Cash, food or vouchers? Evidence from a randomized experiment in Northern Ecuador. IFPRI Discussion Paper [01234]. 2012.

76. Yager JE, Kadiyala S, Weiser SD. HIV/AIDS, food supplementation and livelihood programs in Uganda: a way forward? PLoS ONE. 2011;6(10):e26117. 